\title{
Monitoring and Evaluation Processes on Performance of HIV Prevention Projects For Adolescents in Kisumu County, Kenya
}

\author{
Anthony Wainaina Ndungu, Christopher Mwangi Gakuu, and Harriet Jepchumba Kidombo
}

\begin{abstract}
This research was aimed at exploring how M\&E processes affects performance of HIV prevention projects for adolescents in Kisumu County, Kenya. The study population comprised of HIV prevention projects for adolescents which have been implemented from 2016 - 2018 in Kisumu county Kenya. Target population comprised of adolescents enrolled in HIV prevention projects in 6 organizations in Kisumu County, Kenya as well as staff working in the projects. A sample of 354 respondents were selected from 4483 using stratified, random, and purposive sampling methods. A systemized interview tool and questionnaires were used to collect data. Observed descriptive statistics indicated that M\&E processes had an influence on performance of performance of HIV prevention projects for adolescents in Kisumu County, Kenya. The value of r2 was 0.159 , indicating $M \& E$ processes explained $15.9 \%$ of the variance in performance of $\mathrm{HIV}$ prevention projects for adolescents in Kisumu. The beta coefficient was 0.645 , implying that monitoring $\&$ evaluation process has a significant influence on performance of HIV prevention projects $(\beta=0.645$, $F(1,181)=34.273, P=0.0005<0.05)$. The Beta value indicated that each record variation on performance of HIV prevention programs for adolescent could be linked to $64.5 \%$ variation in M\&E processes.
\end{abstract}

Index Terms - HIV prevention; Participatory M\&E; Project performance; Project M\&E process

\section{INTRODUCTION}

M\&E process is concerned with collection, storage, analysis and finally transformation of data into strategic information so it can be used to make informed decisions for project management and improvement, policy development, and advocacy. Determining fitting M\&E system for projects in different country's is unique to each country's indigenous conditions. One way to do it cannot be the ultimate formula. This study will therefore be sharing results of a study conducted in Kisumu County in Kenya.

Globally, there is a general realization that youths are instrumental in curbing the HIV menace and this has been demonstrated by the world wide indicator that relate to people in this age cohort. Studies conducted have shown that several indicators should be customized for capturing singular efforts towards HIV infection reduction among youths in Kenya and sub Saharan Africa. Teenagers have dynamic characteristics and therefore to succeed in implementing programs that target them, interventions provided must be modeled to specific sub-groups. Therefore, it becomes necessary that that data collected about them to be disaggregated by such characteristics that define each sub group such as age, marital status among others. Additionally, we require refined data that helps us describe and understand dynamics to be considered especially vulnerable youths and children (UNITAID, 2015).

Data that sets apart personal and other factors increasing chances of youth involvement in risky behavior is also required. This can aid project planners understand and monitor the types of behaviors that lead to rise in the risk of HIV transmission among the youths. The study therefore targets to indulge in deep scrutiny of how HIV prevention projects for adolescents are monitored and evaluated as well as establish the effectiveness of M\&E processes applied in their implementation. The output of this study is therefore intended to offer guidance on how to improve performance of such projects, policy development and advocacy as well as provision of tailored services for adolescents to help in elimination of HIV transmission cases.

\section{A. Statement Of The Problem}

Significant amount of funding is channeled by donors and the government in Kenya to implement HIV/AIDS projects. It is required that projects are monitored for control, transparency and accountability for stakeholders, utilization of availed funds and impact, good project performance and documentation. Reviewed reports by National Aids and STI Control Program (NASCOP), indicate that there is lack of accountability for funds provided as well as unmet objectives for key projects in the country that were meant to promote prevention of HIV transmission across various populations. Early this year, pepfar declared heavy cuts in HIV funding supported by the US government. Pepfar said it will reduce its funding to Kenya from Sh50.5 billion this financial year to Sh35 billion next year. HIV prevalence in Kenya stands at about $4.8 \%$, compared to $5.6 \%$ in 2012 . At least 1.5 million people live with the virus, but only one million are on treatment, according to the National Aids Control Council.

Pepfar chief Deborah Birx was quoted saying "We remain concerned about the lack of transparency in the Kenphia survey data as there are other surveys that began after Kenya's, were larger in scope, and we already have full data available for planning and budgeting,". Such and many more consequences are the expected results of inefficient monitoring and evaluation structures and systems. Despite the heavy investments declared to have been made by donors and the government, the NGO projects still fail to provide

Published on November 16, 2019 
credible data on activities conducted. This therefore poses a great challenge in the attempts being made by various stakeholders to eradicate HIV by the year 2030 .

\section{B. Objective Of The Study}

The study sought to establish whether M\&E processes affects (negatively or positively) performance of HIV prevention programs for adolescents in Kisumu County, Kenya.

\section{Hypothesis Of The Study}

The study is anchored on the hypothesis stated below:

H1: M\&E processes significantly affects performance of HIV prevention programs for adolescents in Kisumu, Kenya.

\section{LITERATURE REVIEW}

While the catalytic potential of implementing partners to promote health in local communities is acknowledged, their effectiveness have not been established. Many implementing partners, lack the capacity to manage implementation and results tracking for the projects (Richter et al., 2000). Therefore, as demand for accountability increases, organizations can be seen as if not being optimal in delivering the objectives ( Rugg et al., 1999).

Project success has been defined as that which meets time, cost and quality requirements. This study explores concepts project monitoring and evaluation process as a factor that is likely to affect performance of HIV/AIDS related projects. In the UK, New Zealand and in the United States, Powers, Gregory and Thoutenhood, (1999) and Lang (2002), respectively, discussed programme-monitoring process as a major aspect, which could affect access to education especially if programme daily running indicators are not availed(OECD 2006). Consequently, monitoring should be a well -designed, functioning, and consistent process with tools that can provide factual, authentic, and consistent information needed by project implementers and stakeholders (Kusek \& Rist, 2004). Contrastingly, poorly designed or weak Program monitoring systems may not accurately detect performance indicators; as a result, problem areas may go unnoticed and uncorrected in time.

To project managers and other stakeholders, M\&E processes helps them determine whether their programs are attaining objectives. M\&E enhances accountability in resources utilization (Nyonje, 2012). Data obtained in this process is crucial to facilitate management of the projects. Patton (1997) posits without regard to the processes of gathering data, and reporting, it ends up as a bad evaluation if the data is not utilized. This therefore creates a concern on utilization of M\&E systems output resulting to a growing trend toward promotion of professionalism in the field of M\&E (Quesnel et al., 2010).

A survey conducted by Renard (2007) in 11 states showed that there is a disjointed approach towards M\&E planning, and that the focus is majorly on technical and methodological issues, damaging the whole policy and organizational set-up. The following questions are important, what information is needed and who needs it; what is the frequency of gathering information and how is the information obtained; budget implications and budget holder. Stakeholders are therefore required to possess relevant skills to facilitate this. To control this progression, factual status of M\&E supply and demand requires to be established to point out strengths and weaknesses as the initial step in M\&E planning (Holvoet \& Renard; 2007).

Since teenagers have dynamic characteristics, interventions provided for them must be modeled to specific sub-groups. Therefore, it becomes necessary that that data collected about them to be disaggregated by such characteristics that define each sub group such as age, marital status among others. Additionally, we require refined data that helps us describe and understand dynamics to be considered especially vulnerable youths and children (UNITAID, 2015).

By instituting project performance monitoring at project implementation kick off, lessons can be documented in good time to support appropriate changes in response to varying trends and programming priorities (IFRC, 2007). HIV prevention projects for adolescents in Kisumu were therefore assessed to determine if they have established structures that guarantee quality data collection procedures, standardization of tools, and utilization of data collected in decision making as well as ensuring best implementation approaches are adopted to ensure optimal results are obtained through the projects as intended.

\section{A. Theoretical Framework}

The study was anchored on the following theories:

The Outcomes Theory tries to grow generic understanding regardinghow systems function. It has 2 main concepts; outcomes hierarchies and outcomes systems. According to Duignan (2009) an outcome hierarchy is said to be a grouping of causation agents. These are seen as cascading outcomes in which each outcome may be brought out by others and may itself lead to others resulting from it. This study sought to attribute improvement in performance of HIV prevention projects for adolescents to effectiveness of M\&E process. The theory targets to bring together the design and operationalization of outcomes systems.

Experiential learning theory and evaluation utilization model in which learning is described as the procedure of acquiring knowledge through experience. The theory specifies 4 ways to learn; solid experiences that gives a foundation to observe reflectively. This theory takes a emphasizes how experiences of all kinds whether resulting from sensory effects, emotions or the surroundings, affects learning process. This mode of learning may aid individuals in examining their capabilities inn comprehending new things. However the position of nonreflective experience in acquisition of new knowledge does not feature clearly. There are also claims of the theory being constraining/limiting as compared to others

\section{B. Conceptual Framework}


The study aimed at exploring how monitoring \& evaluation process influences performance of HIV prevention projects for adolescents in Kisumu County, Kenya. Three key indicators of $\mathrm{M} \& \mathrm{E}$ processes were used including $\mathrm{M} \& \mathrm{E}$ output utilization in decision making, capacity building of M\&E staff and existence and utilization of a central database. The relationship among the specified study variables is shown in Figure 1.

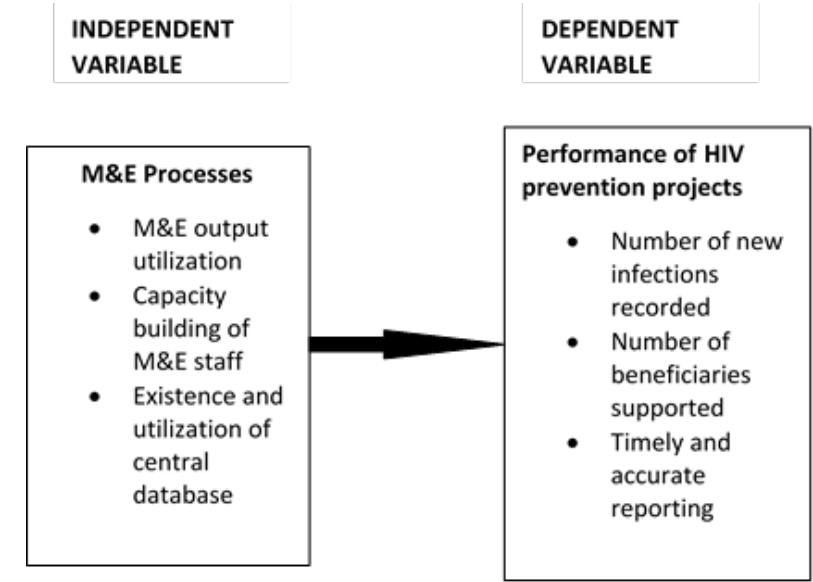

Fig.1: Conceptual framework for M\&E process influence on performance of HIV prevention projects for Adolescents

\section{Methodology}

The study applied a combination of descriptive survey together with correlation design. This combination was chosen because descriptive and inferential analysis were conducted simultaneously. Target population comprised of adolescents enrolled in HIV prevention projects in 6 organizations in Kisumu, County, Kenya implemented within 2016 - 2018. A combination of census, stratified and purposive sampling methods were applied. All NGOs were included in the first stage. In the second stage 340 adolescents were randomly selected from 4483 adolescents enrolled by the organizations who are beneficiaries of the project. In the third stage, parents, project managers, M\&E officers, and government officials, were chosen using purposive sampling techniques sampled above. To ensure construct validity, the instruments were reviewed by experts who included professors and consultants. Verification of internal validity was done through triangulation where questionnaires had similar quizzes synthesized according to responses from various respondents (Merriam, 1998). To ensure reliability a pilot study was carried out in three organizations out of the six which included 20 respondents.

\section{FINDINGS AND DISCUSSIONS}

A sample size of 354 respondents from a research population of 4483 adolescents enrolled in the projects was selected. Questionnaires were used as the key instruments for data collection. Three hundred and twenty (320) questionnaires were returned which was a return rate of $90.4 \%$ which was considered sufficient for this study. $60 \%$ response rate and beyond is both desirable and achievable in social sciences though in some cases it could go lower according to Richardson (2005). Document analysis was used to collect secondary data. The targeted documents were from one organization from each sector that made up the target population. These organizations could only provide their project proposals and work plans as the only tools used in the planning of $\mathrm{M} \& \mathrm{E}$, the main reference being the logical framework. There were documents showing a detailed implementation plan but there was no sufficient evidence of monitoring \& evaluation capacity building activities for particular areas. There were; 2 project proposals (only sections of them were given because organizations were reluctant to give them), 2 work plans, and 2 power point presentation of M\&E reports. The purpose of this review was also for triangulation. Normality of the distribution of the population was achieved by making sure that there was no bias in picking the respondents from all the wards. Every effort was made to use the same proportion across the wards based on the overall number of respondents. Table 4.1 shows the targeted respondents and sample size in each category.

\begin{tabular}{lcc}
\multicolumn{1}{c}{ TABLE 4.1: POPULATION AND SAMPLE SIZE } \\
\hline Category & N & n \\
\hline Adolescents & 4483 & 348 \\
M\&E Managers & 6 & 2 \\
Project Managers & 6 & 2 \\
Policy Makers & 5 & 2 \\
\hline TOTAL & $\mathbf{4 , 5 0 0}$ & $\mathbf{3 5 4}$
\end{tabular}

\section{Key}

$\mathrm{N}=$ target population (Total 4,483)

$\mathrm{n}=$ sample size (Total 354)

$\mathrm{R}=$ Number that responded (Total 345)

\section{A. Distribution of Respondents by Level of Education}

The options that were provided in this item were: primary level, secondary level and tertiary level. The responses were as shown in Table 4.2.

TABLE 4.2. RESPONSES BASED ON LEVEL OF EDUCATION

\begin{tabular}{llc}
\hline Level of Education & Frequency (F) & Percentage (\%) \\
\hline Primary school & 119 & 37.2 \\
Secondary school & 181 & 56.6 \\
Tertiary institution & 20 & 6.2 \\
\hline Total & $\mathbf{3 2 0}$ & $\mathbf{1 0 0}$ \\
\hline
\end{tabular}

Table 4.2 highlights that most respondents were either in secondary school or had completed secondary level of education $(56.6 \%) ; 37.2 \%$ had acquired primary level of education while $6.2 \%$ of those interviewed had tertiary education(polytechnic, college or university).

\section{B. Distribution Of Respondents By Gender}

To establish gender representation of respondents, respondents were required to indicate whether they were either male or female. Most projects tend to offer services with inclination on female gender since young girls are 
considered to be more vulnerable than boys

TABLE 4.3 RESPONSES BASED ON RESPONDENTS GENDER

\begin{tabular}{cll}
\hline Gender & Frequency (F) & Percentage (\%) \\
\hline Females & 177 & 55.3 \\
Males & 143 & 44.7
\end{tabular}

\begin{tabular}{lll} 
Total & $\mathbf{3 2 0}$ & $\mathbf{1 0 0 . 0}$ \\
\hline
\end{tabular}

Data from table 4.3 above shows that $55.3 \%$ were female and $44.7 \%$ recorded as male. The gender spread recorded was favorable providing a reasonably inclusive environment for both boys and girls to be included in the study in good proportions

\section{Responses Based On Marital Status}

Respondents were asked to indicate their marital status on whether they were single, married, divorced or separated. This information was considered important to understand the dynamics of different respondents in a peer based setting. This information would also be necessary in describing the social setting and vulnerability differences between married and unmarried. The results were as shown in table 4.4.

TABLE 4.4: RESPONSES BASED ON MARITAL STATUS

\begin{tabular}{lll}
\hline \multicolumn{1}{c}{ Marital Status } & Frequency(F) & Percentage (\%) \\
\hline Single & 248 & 77.5 \\
Married & 36 & 11.3 \\
Divorced/Separated & 31 & 9.7 \\
Widowed & 5 & 1.5 \\
\hline \multicolumn{1}{c}{ Total } & $\mathbf{3 2 0}$ & $\mathbf{1 0 0 . 0}$ \\
\hline
\end{tabular}

The results show that $77.5 \%$ of respondents interviewed were single. Most respondents in this category were school going. Out of the total population questioned $11.3 \%$ indicated that they were married. This information would later be used by the researcher to establish the influence of early marriages among adolescents in the region. A small percentage (9.7\%) indicated that they had earlier been married but were now divorced or separated. Others indicated that they were widowed $(1.5 \%)$.

\section{Distribution Of Respondents By Duration Of Engagement In The Project}

Respondents were also asked to indicate how long they had been engaged in the projects. This information was necessary to avoid bias on responses from those who may have not been in the project long enough to share experiences. Results were as shown in Table below

TABLE 4.5: RESPONSES BASED ON DURATION OF ENGAGEMENT IN THE PROJECT

\begin{tabular}{cll}
\hline Duration of engagement & Frequency & Percentage \\
\hline 0 months - 3 months & 41 & 12.8 \\
4 months - 6 months & 12 & 3.8 \\
7 months - 9 months & 80 & 25.0 \\
10 months - 12 months & 120 & 37.5 \\
Above 12 Months & 59 & 18.4
\end{tabular}

\begin{tabular}{lll} 
Non- responsive & 8 & 2.5 \\
\hline Total & $\mathbf{3 2 0}$ & $\mathbf{1 0 0}$ \\
\hline
\end{tabular}

The results indicate that $12.8 \%$ of the respondents had been enrolled in the project for utmost 3 months while $3.8 \%$ had been involved for a period between 4 to 6 months. This result implies that $25 \%$ of the respondents had been involved in the project for a period between $7-9$ months. Although majority $(37.5 \%)$ of the respondents had been involved for 12 months or less in the projects, this was not an indicator of the respondents experience in the projects. Interviews conducted in this study indicated that many respondents had worked with similar projects for more than 3 years which was considered in this study sufficient to make objective responses on the performance of HIV prevention projects.

\section{E. Testing Statistical Assumptions}

This section shows how normality, multicollinearity and singularity were conducted during tests of various statistics were controlled. In addition, likert scale and its application in this process is also discussed

\section{F. Normality Test}

Most parametric tests are anchored on the assumption that populations being studied have normal distribution. When this assumption is not true, any conclusion derived from it cannot be taken in as accurate and reliable (Thode, 2002). For small sample sizes (less than 40), these tests have little power to test normality thus they most often pass the test (Oztuna, Elhan \& Tuccar 2006). But for large samples, normality test are important so as to give credibility to the hypothesis testing. Besides estimating normality visually, normality test should be done. This study used Shapiro-Wilk W to achieve better power (Peat and Barton, 2005). The efficiency of determining if the population providing the sample is normally distributed or otherwise.

The value of $\mathrm{w}$ being less than and close to one is an indication of normal distribution. The judgment followed these guidelines; W statistics $=1$ therefore indicates perfection in normality. SPSS software tests for both Shapiro Wilks and Kolmogorov. The choice of which between the two follows recommendations that for test that have a small sample of $n=3 \Rightarrow 2000$, Shapiro Wilks is applied while Kolmogorov-Smirnov is applied where $n>2000$. Shapiro Willks was used in this case. In this test statistics stands for W. Following a SPSS run, the following results were obtained as shown in Table 4.6

\begin{tabular}{llll} 
TABLE 4.6: NORMALITY TEST & & & \\
\hline Variables & Statistic & df & Sig. \\
\hline M\&E process & .983 & 182 & .027 \\
Project performance & .997 & 182 & .002 \\
\hline
\end{tabular}

All the statistics in the test (W) were above 0.96 . The list was 0.963 and the highest was 0.997 . None of the variables had $\mathrm{W}$ statistics $=1$, therefore none was a perfectly normal distribution but the scores were significantly closer to 1 which was acceptable since, perfectly normal distribution is rarely 
achievable.

\section{G. Likert Scale As An Interval Measure}

Likert scale types of questions were used in the study. These are differentiated as likert item; when an item is used to measure a single variable and likert scale; when a number of items are arranged as a group intended to measure a single variable (Brown, 2011).

The equidistance issue in likert scale has been the point of departure for the debate of whether the scale is ordinal or interval but the creation of a composite score as argued by Boone and Boone (2012) gives this debate another statistical dimension. Composite score were used in analysis and decision rules after analysis of mean scores were guided by the logical equal levels of the score approximated to the first decimal point in line with equidistance arguments (Carifio and Rocco, 2007; Bertram, 2007; lantz, 2013). This study used one verbal anchors; $1=$ Strongly Disagree (SD); $2=$ Disagree (D); $3=$ Neutral (N); 4= Agree (A); 5= Strongly Agree (SA) Therefore the judgment rule followed this argument; SA would be for values lying between 1 and 1.8; $\mathrm{D}$ for values between 1.8 and 2.6; $\mathrm{N}$ for values between 2.6 and 3.4; A for values between 3.4 and 4.2; S.A for values between 4.2 and 5.0. This establishes an equidistance of 0.8 .

Correlations coefficient was used to measure relationships. Decision rule followed Cohen (1988) suggested guidelines that r-value of between .10 to .29 means weak correlation while that between .30 to .49 means average and that between .50 to 1.0 means there exists strong correlation. A minus sign in the value shows the direction not magnitude. These guidelines were also used by Shirley, Stanley and Daniel (2005).

\section{H. Tests for multi-co linearity and singularity}

Linear assumptions of singularity and multi-collinearity were also checked before undertaking regression analysis through correlations. During data analysis, singularity is established where an independent variable (I.V) is formed from joining together other I.Vs. On the other hand, multicollinearity is checked by analyzing the tolerance values under collinearity to ensure that the assumption is not violated (Asteriou and Hall, 2011). In particular, 1 - R2 values should be more than 0.1 which implies low multicollinearity (Shirley et al., 2005). If two variables are perfectly collinear, singularity is said to exist and an exact linear relationship exists among predictors with a correlation coefficient equal to 1.0 or -1.0 . In this study, multi-co linearity didn't exist between the predictor variables.

Analysis of Influence of M\&E process on performance of HIV prevention projects

The study sought to investigate M\&E processes conducted in HIV prevention projects for adolescents and their effectiveness. This was drawn from responses on ten items made by the respondents regarding the stated vaiable. Results were as displayed in Table 4.7 below

TABLE 4.7 INFLUENCE OF M\&E PROCESSES ON PERFORMANCE OF PROJECTS

\begin{tabular}{|c|c|c|}
\hline $\begin{array}{ll}\text { Scale } & \text { of } \\
\text { megsurement } & \end{array}$ & Freq & e \\
\hline
\end{tabular}

\begin{tabular}{|c|c|c|c|c|c|}
\hline & & & tage & & Dev. \\
\hline \multirow[t]{2}{*}{1.} & Strongly & 107 & & 4.002 & 0. \\
\hline & Agree & 140 & $33.4 \%$ & & 941 \\
\hline \multicolumn{6}{|c|}{ 2. Agreed } \\
\hline & & & $48.8 \%$ & & \\
\hline \multirow[t]{2}{*}{3.} & Neutral & 44 & & & \\
\hline & & & $13.8 \%$ & & \\
\hline 4. & Disagreed & 21 & & & \\
\hline \multirow[t]{3}{*}{5.} & Strongly & 8 & $6.5 \%$ & & \\
\hline & Disagree & & & & \\
\hline & & & $2.5 \%$ & & \\
\hline \multicolumn{2}{|c|}{ Total } & 320 & $100 \%$ & & \\
\hline
\end{tabular}

Results indicate that majority of respondents were in support of the items posed with $107(33.4 \%)$ strongly supporting and $140(48.8 \%)$ while $21(6.5 \%)$ and $8(2.5 \%)$ were not in support and strongly disapproved the statements respectively. Forty one (41) respondents representing 13.1\% could neither agree nor disagree. With a composite mean of 4.002 and S.D of 0.9405 it implies that majority $247(77.2 \%)$ were in agreement that performance of projects was influenced by M\&E processes.

\section{Tests of Hypothesis}

Hypothesis testing was done to establish the statistical significance of the $M \& E$ processes on performance of the projects. P-values represents 0.05 significant level. Hypothesis was either accepted or rejected at values of F-ratio in which $\mathrm{p}$ was less than 0.05 . The decision rule adopted was; if $\mathrm{p}$ is less than alpha, null hypothesis is rejected and if $\mathrm{p}$ is greater than alpha it was accepted. Regression model was applied to establish strength I.V (M\&E process) as far as their relationship with the dependent variable is concerned.

H1: M\&E processes significantly affects performance of HIV prevention projects for adolescents in Kisumu County, Kenya.

Composite index for M\&E process and performance of projects were used as the predictor variables. The following linear regression model was used; $y=a+p 2 X 2+e$ in which; $\mathrm{y}=$ Performance of HIV prevention projects

$\mathrm{a}=$ constant

$\beta 2=$ Beta coefficient

$\mathrm{X} 2=\mathrm{M} \& \mathrm{E}$ processes

$\mathrm{e}=$ error term

Results showed that $r=0.487$ meaning M\&E processes had moderate influence on performance of HIV prevention projects since P-value was less than 0.05 . R squared was 0.159 , hence $\mathrm{M} \& \mathrm{E}$ processes explain $15.9 \%$ of variation of the respondent score on performance of HIV prevention projects while $84.1 \%$ is as a result of other factors. With w value of 2.016, autocorrelation could have been registered.

With $\mathrm{F}(1,181)=34.273, \quad \mathrm{P}=0.0005<0.05$ recorded the implication was that M\&E processes have statistically significant influence on Performance of HIV prevention

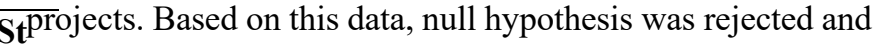
alternate hypothesis accepted. Therefore M\&E processes detrmines Performance of HIV prevention projects in Kisumu 
County at 0.05 level of significance.

\section{RECOMMENDATIONS}

Based on data analysed in this study, there was notable gaps in skills and capacities of M\&E staff working for the projects. $28.3 \%$ indicating that they had never seen the logical framework for the projects they were implementing though it was in existence. The study therefore recommends that the project managers should conduct deliberate trainings and capacity building activities to equip their M\&E staff with necessary data correction analysis and utilization skills to aid in improvement of project performance.

Compliance in reporting was also identified as a major gap with key representatives $(32.4 \%)$ indicating that they wouldn't mind delaying sharing their monthly reports provided their last submission is "accurate".

\section{CONCLUSION}

Conclusion was made based on the obtained results indicating that with $\mathrm{F}(1,181)=34.273, \mathrm{P}=0.0005<0.05$, M\&E process is a great contributor to performance of HIV prevention projects and therefore their implementation and compliance should be emphasized if the project outcomes are to be optimized.

\section{REFERENCES}

[1] Binnendijk, A. L. (1989). Donor agency experience with the monitoring and evaluation of development projects. Evaluation Review, 13(3), 206-222.

[2] Kimberlin, C. L., \& Winterstein, A. G. (2008). Validity and reliability of measurement instruments used in research. American Journal of Health-System Pharmacy, 65(23), 2276-2284. doi:10.2146/ajhp070364

[3] Creswell, J. W. (2013). Research design: Qualitative, quantitative, and mixed methods approaches. Sage Publications, Incorporated.

[4] M. B. Kasmani, "A Socio-linguistic Study of Vowel Harmony in Persian (Different Age Groups Use of Vowel Harmony Perspective,' International Proceedings of Economics Development and Research, ed. Chen Dan, pp. 359-366, vol. 26, Singapore, 2011.

[5] Cristina S. (2012). Resource Allocation in Project Management. International Journal of Economic Practices and Theories, Vol. 2, No. 4, 2012 (October), e-ISSN 2247-7225.

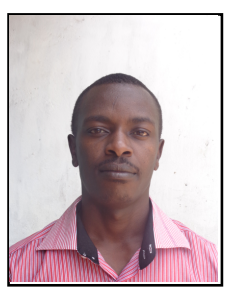

Anthony Wainaina Ndungu is from Kiambu County in, Kenya 18th October 1986. Kenyan based degrees :,PhD in Project planning and Management (Monitoring and Evaluation) from University of Nairobi 2019, Project planning and Management (Monitoring and evaluation) from University of Nairobi, 2015, Bachelor of science in Computer Technology from Jomo Kenyatta University of Agriculture and Technology 2010. $\mathrm{He}$ has been involved in implementation of national development and health projects with various NGOs and INGOs in Kenya for more than 8 years. He's currently a lecturer at the university of Nairobi, ODEL campus.

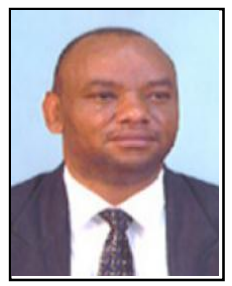

Prof. Christopher Mwangi Gakuu is a Professor and Director, ODEL in the School of Continuing and Distance Education at the University of Nairobi. He holds a $\mathrm{PhD}$ in Distance Education from the University of Nairobi, an MBA. from United States International University (USIU) and a Bachelor of Education degree from Kenyatta University and several other diplomas. He has previously served as a high school where he rose to the position of Deputy Principal. He was involved in the AVU Capacity Enhancement Programme(ACEP) on the Management and Governance of online programmes.

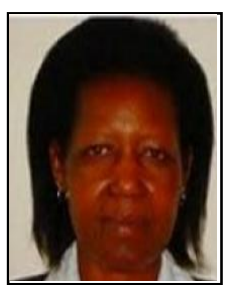

Prof Harriet Kidombo is a Professor in Open, Distance University of Nairobi where she's involved in the development, management and evaluation of academic and management of adult, open, distance and e-Learning programmes. She have experience of more than 20 years in the use of adult and distance learning methodologies to deliver education. This includes a short attachment at the University of South Africa (UNISA). She holds a $\mathrm{PhD}$ in Business Administration from the University of Nairobi, an M.Sc. in Human Resource Development from the University of Manchester, UK and a Bachelor of Arts Degree from the University of Nairobi. She have also undertaken a training of trainers AVU Capacity Enhancement Programme (ACEP) on the Material development, Governance and Technology and Delivery of online programmes with the Association of Universities and Colleges of Canada. 